\title{
Analysis of Rewards Results of Banking Shares Book III Registered in Indonesia Stock Exchange
}

\author{
Noviesag Artanto ${ }^{1}$, Augustina Kurniasih ${ }^{2}$ \\ \{noviesag@gmail.com¹, augustina.kurniasih@mercubuana.ac.id² \\ Universitas Mercu Buana Jakarta, Indonesia ${ }^{12}$
}

\begin{abstract}
Stock is one of the investment instruments that many investors choose. One of the industrial sectors on the Indonesia Stock Exchange is the financial sector. Banking is one of the financial sub-sectors. Book III banking stocks are included in the top 50 market capitalization category on the IDX in 2019. Book III bank stock returns fluctuate, indicating volatility that occurs. This study analyzes the stock returns of Book III using the ARCH / GRACH approach. The study also aims to find the best ARCH / GARCH model to solve the volatility problem that occurs in Book III stock returns. The results showed that the highest average return was generated by MAYA shares. For the ARCH / GARCH approach, the best model in the volatility of return of banking stocks in Book III, the majority use the GARCH model $(1,1)$.
\end{abstract}

Keywords: Banking Stocks, ARCH, GARCH, Volatility

\section{Introduction}

Banking is a financial industry that functions as an intermediary in collecting and channeling public funds. In Indonesia, banking plays an important role in driving the national economic sector. Based on Bank Indonesia regulation Number 14/26 / PBI / 2012, the division of commercial bank business groups is divided into 4 groups according to core capital, namely Bank Book I, Bank Book II, Bank Book III, and Bank Book IV. Bank Indonesia Regulation Number 14/26 / PBI / 2012 concerning Business Activities and Office Networks Based on Bank Core Capital states that Banks with Core Capital are at least IDR 5,000,000,000,000.00 (five trillion rupiah) to less than IDR 30,000,000. 000,000.00 (thirty trillion rupiah) is a Bank in the category of Banking Book III (three). The amount of core capital shows the amount of commitment given by shareholders to the sustainability of the bank, both individually and in relation to the banking industry as a whole.

Stocks are an investment instrument that many investors choose because stocks are able to provide an attractive rate of return. In Indonesia, the place that is the center of transactions between capital seekers who want to build a company and investors who have money and are interested in investing is the Indonesia Stock Exchange. In 2018, based on data on the IDX, 12 BUKU III banking stocks were traded. The Indonesian Stock Exchange annually issues a classification of shares. One of them is the top 50 companies with the largest market capitalization. Market Capitalization (Market Capitalization) is the value or price of a company calculated from the total value of the shares outstanding. Market capitalization also means that if the higher the market capitalization, the higher the number of shares outstanding on the IDX, so this also proves 
that the company is increasingly active in trading shares to investors. Based on the list of 50 largest market capitalizations issued by the IDX in 2019, 5 BUKU III Banks are included in the list of categories, namely Bank Danamon (BDMN), Bank BTN (BBTN), Bank BTPN (BTPN), Bank Mega (MEGA), and Bank Mayapada (MAYA).

Apart from issuing a list of stock capitalization, the Indonesia Stock Exchange (IDX) has also issued a list of stock groups taking into account the liquidity factor known as the IDX80 index list. The IDX80 Index List is a collection of stocks selected by considering liquidity factors, namely the value and frequency of transactions on the regular market, the number of transaction days on the regular market and free float stock market capitalization, as well as fundamental factors that include financial performance and compliance. Based on the attachment to the IDX announcement No Peng-00021 / BEI.OPP / 01-2019 Book III banking shares are included in the list. Stocks are an investment instrument that many investors choose because stocks are able to provide an attractive rate of return. When investing, investors expect to get the return that they expect, but in Book III banking stocks the returns of the five banks fluctuate. Returns that fluctuate occur because stock prices are not constant and change from period to period. Changes in stock returns that always fluctuate are a sign of volatility. Volatility is an unstable and difficult to predict event. This volatility often shows a high fluctuation then low and then high again, this is due to the variance of errors that are not constant.

The leading theory used in measuring volatility was proposed by [1]. Engle wrote the $\mathrm{ARCH}$ (Autoregressive Conditional Heteroscedasticity) theory which is used to measure the estimated means and variance of inflation in the UK due to the emergence of volatility clustering or heteroscedasticity. This theory was then refined by [2] bringing up the GARCH (Generalized Autoregressive Conditional Heteroscedasticity) theory which had a more flexible leg level. [2] use GARCH in measuring the exchange rate and stock price index. Research in resolving volatility in changes in stock returns has been carried out by many previous researchers, such as [3] stated that the symmetric GARCH worked well in the precrisis period and the asymmetric GARCH model can be a better model in capturing the volatility of the Malaysian stock market. Research [4] states that the stock market volatility in Indonesia using the ARCH model can be seen that the causes of volatility that occur in stock prices in Indonesia are caused by interest rates, inflation and exchange rates. Variance is usually represented by the standard deviation indicating the standard of change. One way to measure volatility is using GARCH / ARCH (Generalized / Auto Regressive Conditional Heteroskedastic).

Measurement of risk for stock returns that fluctuate symmetrically can use the ARCH / GARCH method, as has been done. According to [5] found that the arch model can handle volatility other than in stocks, namely in bitcoin. According to [6] that strong volatility has a grouping of variances, and the ARCH model can adjust for these problems. It is found that the ARCH / GARCH model can be used symmetrically and asymmetrically in assessing volatility and forecasting stock index returns on the Indonesia Stock Exchange. [7] explained that ARCH modeling can be used to estimate the volatility of returns in the stock market. [8] found that the GARCH model can be used to estimate the movement of the closing price of shares from past stock components where past stock prices affect the formation of future stock prices. [9] researched the real estate industry in China. It is concluded that to prevent uncertainty and stock market risk and to measure the volatility of stock returns, the GARCH model is effective. Similar to [10] explained that the GARCH model can be applied in the Chinese stock market and get a significant forecast estimate. [11] that the GARCH type model has a good model of stock market volatility and returns investigations, many experts 
suggest that the GARCH model gives better results combined with other statistical techniques. [12] using the ARCH GARCH method in exploring the volatility of the stock market in Zimbabwe, and using a symmetrical and asymmetrical model of ARCH, it is proven that the Exponential GARCH Model $(1,1)$ is proven to be an efficient model for modeling volatility.

According to [13] states that ARCH / GARCH shows better results with less errors than other methods. Research [14] explained that the forecasting model with GARCH obtained statistically significant results compared to other volatility forecasting models such as MLP, GRNN, GMDH, RF, QRRF, and QRNN on eight financial data sets. It was also found that ARCH / GARCH could be used to study voltages in other fields such as agriculture ([15] \& [16]), and gold by [17]-[26] are similar in relation to the use of the ARCH / GARCH method in dealing with the symptoms of volatility. and [27]. This study aims to analyze (1) how much return is obtained by investors when investing in Book III banking stocks and (2) to analyze how to overcome the volatility symptoms that occur in the return of banking stocks in Book III listed on the Indonesia Stock Exchange.

\subsection{Literature Review}

Volatility is a concern and an important subject of study in financial research. Volatility is linguistically unstable, a condition where data moves up and down, sometimes in an extreme way. One of the main applications of volatility modeling is to measure risk. According to [28] find that market volatility information from both trading and nontrading periods leads to improved portfolio performances. Volatility reflects the level of risk of an investment asset. A high level of volatility indicates a high risk and also a high rate of return. Knowing the level of volatility in investment assets will make investors wiser in managing their investments.

Stock return is also known as share income and is the change in the value of the stock price from period $\mathrm{t}$ to $\mathrm{t}-1$. The higher the change in stock prices, the higher the resulting stock return. Stock returns can be calculated using the formula:

$$
\text { Return }=\left(\frac{P_{t}-P_{t-1}}{P_{t-1}}\right)
$$

note:

$P_{t}=$ The closing price of shares on the month $\mathrm{t}$

$P_{t-1}=$ The closing price of shares on the month to t-1

The time series analysis model that allows heteroscedasticity is the ARCH model introduced by [1]. ARCH model is used to model the residual variance depending on the squared residue in the previous period by autoregression (self-regression), or in other words, this model is used to model conditional variance. [2] stated that the residual variance depends not only on the residuals in the past but also the variance of the residuals in the past. This model from Bollerslev in 1986 is known as the Generalized Autoregressive Conditional Heteroscedastic (GARCH) model.

\section{Research Method}

This study uses a quantitative descriptive research design to find the returns that investors will receive when investing in Book III banking stocks listed on the IDX. And provides information related to the volatility that occurs in Book III banking stocks. The 
data used in this research is the monthly closing stock price of book III banking which is collected by documentation method through the website www.finance.yahoo.com. The sample consists of 5 (five) shares of book bank III, namely BBTN shares, BDMN shares, BTPN shares, MAYA shares and MEGA shares.

The analysis begins with (1) calculating the return of each stock, (2) checking data stationarity, (3) descriptive statistics of heteroscedasticity effects (4) correlogram test (5) estimating the best ARCH / GARCH optimum model. Return is calculated using equation (1). Data stationarity checks are carried out using differencing and log transformations if the data obtained is not stationary. In the stationary time series data, it is necessary to minimize model errors. The best ARCH / GARCH models are those that have significant parameter estimates and minimum AIC and SIC values.

\section{Results and Discussion}

\subsection{Stock Price}

The monthly closing share prices of BBTN, BDMN, BTPN, MEGA \& MAYA Bank throughout 2010-2019 all shares fluctuated. The most volatile stocks are BDMN shares. This indicates that BDMN bank share prices based on the stock price range have a higher risk.

Table 1. Book III Stock Price Range for the 2010-2019 Period

\begin{tabular}{ccc}
\hline No & Stocks & Price Range \\
\hline 1 & BBTN & Rp 761 - Rp 3.653 \\
2 & BDMN & Rp 2.059 - Rp 7.493 \\
3 & BTPN & Rp 913 - Rp 4.945 \\
4 & MEGA & Rp 898 - Rp 6.189 \\
5 & MAYA & Rp 415 - Rp 9.100 \\
\hline
\end{tabular}

\subsection{Return}

After the BUKU III banking stock price from January 2010 to December 2019 is obtained, the next step is to calculate the return of each Book III banking stock. With the help of the Eviews program, the researcher found that there was a symptom of volatility in the return of book III banking stocks, not only volatility but also heteroscedasticity symptoms in that return. Based on the returns obtained for BBTN shares experiencing relatively high fluctuating movements in 2012 and 2018, in BDMN stocks relatively high fluctuation movements also occurred in 2018 and 2019. For BTPN stock returns experienced the highest fluctuating movements in 2018, on stock returns MAYA, the highest fluctuating movement occurred in 2013 and for MEGA stock returns, the highest fluctuating return movement was in 2014 and 2017.

Based on this phenomenon, it indicates that there is volatility that occurs in clustering. According to [28] volatility clustering, which is a condition where the movement of time series data tends to go up or down drastically and suddenly under certain conditions or events, until it finally calms down again. In proving the existence of the symptoms of volatility and heteroskedasticity, the next stage is carried out in the form of a descriptive analysis of each bank return in Book III. 


\subsection{Descriptive Analysis}

The return value (return) generated by each share of Book III is presented in the table as follows:

Table 2. Return of Book III Shares for the 2010-2019 Period

\begin{tabular}{llllllll}
\hline $\begin{array}{l}\text { Stocks } \\
\text { Name }\end{array}$ & $\begin{array}{l}\text { Min } \\
\text { Return }\end{array}$ & $\begin{array}{l}\text { Max } \\
\text { Return }\end{array}$ & Mean & $\begin{array}{l}\text { Std. } \\
\text { Dev }\end{array}$ & Skewness & Kurtosis & Probability \\
\hline BBTN & $-0,288$ & 0,208 & 0,0022 & 0,107 & $-0,441$ & 3,036 & 0,144 \\
BDMN & $-0,468$ & 0,383 & 0,006 & 0,105 & $-0,344$ & 6,647 & 0,000 \\
BTPN & $-0,203$ & 0,220 & 0,001 & 0,073 & $-0,004$ & 3,759 & 0,239 \\
MAYA & $-0,714$ & 0,526 & 0,001 & 0,184 & $-0,753$ & 5,660 & 0,000 \\
MEGA & $-0,334$ & 0,285 & 0,007 & 0,089 & $-0,120$ & 5,852 & 0,000 \\
\hline
\end{tabular}

Based on the descriptive analysis in Table 2, it shows that BBTN's stock return, the average value of BBTN's return, is 0.00225 . The minimum return is -0.288 with a maximum return of 0.208 , the standard deviation shows the number $10.72 \%$, this value further confirms the volatility symptoms that occur in BBTN stock returns. The skewness value is $-0.441<0$, this indicates that the data has heteroscedasticity symptoms. The kurtosis value is 3.036 more than the normal standard deviation $(+3)$, and the probability value is $0.144>0.005$, in this case the data is normally distributed. BDMN shares generate an average return value of 0.0062 . The minimum return (return) is -0.4687 and the maximum return is 0.3832 . The standard deviation shows $10.53 \%$, this value further confirms the volatility symptoms that occur in BDMN stock returns. The skewness value is $-0.3444<0.00$, this indicates that the data has heteroscedasticity symptoms. The probability value is $0.00<0.005$, in this case the data is not normally distributed.

BTPN shares generate an average return value of 0.001254 . The minimum return is 0.2033 and the maximum return is 0.2204 . The standard deviation shows a figure of $7.31 \%$, this value further confirms the volatility symptoms that occur in BTPN's stock returns. The skewness value is $-0.004<0.00$, this indicates that the data has heteroscedasticity symptoms. The probability value is $0.23>0.005$, in this case, the data is normally distributed. Based on the results of descriptive analysis, BTPN stock return data has heteroscedasticity symptoms and is normally distributed. MAYA shares generate an average return value of 0.00117 . The minimum return is -0.714 and the maximum return is 0.526 . The standard deviation shows the number $18.14 \%$, this value further confirms the volatility symptoms that occur in MAYA stock returns. The skewness value is $-0.7533<0.00$, this indicates that the data has heteroscedasticity symptoms. The probability value is $0.00<0.005$, in this case the data is not normally distributed. Based on the results of descriptive analysis, the MAYA stock return data has heteroscedasticity symptoms and is not normally distributed.

MEGA shares generate an average return value of 0.0076 . The minimum return is 0.3394 and the maximum return is 0.285 . The standard deviation shows the number $8.99 \%$, this value further confirms the volatility symptoms that occur in MEGA stock returns. The skewness value is $-0.1201<0.00$, this indicates that the data has heteroscedasticity symptoms. The probability value is $0.00<0.005$, in this case the data is not normally distributed. Based on the results of descriptive analysis, MEGA stock return data has heteroscedasticity symptoms and is not normally distributed. 


\subsection{Data Stationarity Test}

Table 3. Data stationarity test results

\begin{tabular}{lll}
\hline No & Stocks Name & Sign. \\
1 & BBTN & 0.5285 \\
2 & BDMN & 0.1456 \\
3 & BTPN & 0.0775 \\
4 & MEGA & 0.9993 \\
5 & MAYA & 0.9997 \\
\hline
\end{tabular}

Table 3 shows that from the closing stock prices of BBTN, BDMN, BTPN, MEGA \& MAYA are not stationary, so first order differencing is carried out. And after the first order differencing is obtained the probability value of ADF $\mathrm{r} 0.000$. This value is less than the significance level of $5 \%$ so that the stock data of BBTN, BDMN, BTPN, MEGA \& MAYA are stationary.

\subsection{Model ARCH/GARCH}

Model selection identification is done to get an overview of the time series model during the observation period. Simultaneous modeling of variance models (ARCH / GARCH) for each data.

Table 4. Summary of Best Models of ARCH / GARCH Banking Book III

\begin{tabular}{ccccccccc}
\hline No & $\begin{array}{l}\text { Stocks } \\
\text { Name }\end{array}$ & ARCH & GARCH & $\begin{array}{l}\text { R- } \\
\text { square }\end{array}$ & $\begin{array}{l}\text { Heterosce } \\
\text { dasticity }\end{array}$ & Normality & AIC & SIC \\
\hline 1 & BBTN & $(1: 1: 1)$ & $(1: 1)$ & 0,61 & Fulfilled & Fulfilled & $-1,62$ & $-1,16$ \\
2 & BDMN & $(1: 1: 1)$ & $(1: 1)$ & 0,52 & Fulfilled & Fulfilled & $-1,48$ & $-1,11$ \\
3 & BTPN & $(1: 1: 1)$ & $(1: 1)$ & 0,48 & Fulfilled & Fulfilled & $-1,84$ & $-1,56$ \\
4 & MAYA & $(1: 1: 1)$ & $(1: 1)$ & 0,51 & Fulfilled & Fulfilled & $-1,90$ & $-1,76$ \\
5 & MEGA & $(2: 0: 1)$ & $(2: 1)$ & 0,04 & Fulfilled & Fulfilled & $-0,53$ & $-0,36$ \\
\hline
\end{tabular}

Based on the research that has been done, it shows that in book III banking stock returns there are symptoms of volatility and heteroscedasticity, which means that the residual variants of this data are not constant and change from one period to another. In solving the volatility and heteroscedasticity symptoms that occur, the results of the study show that the coefficient variant equation on GARCH $(1,1)$ is the best GARCH model for stock returns of BBTN, BDMN, BTPN and MAYA. For the problem of volatility on stock returns, MEGA uses the GARCH model $(2,1)$.

The results of this study in overcoming the symptoms of volatility and heteroscedasticity using GARCH support research [1] on a concept called ARCH (Autoregressive Conditional Heteroscedasticity). ARCH is used to estimate the presence of heteroscedasticity in a time series data so that the forecasting results can be more accurate, and [2] that the GARCH model can estimate the level of volatility of a stock in the capital market. In addition, the results of the best GARCH model on bank stock returns in Book III also support previous research conducted by [10] that the GARCH model is also used in resolving the volatility symptoms that occur in stock market returns in China.

The results of this study also support [29] who use GARCH $(1,1)$ in overcoming volatility on the stock market in India. This study is also in line with research [30] which examines the volatility that occurs in stock returns in Nigeria and uses the GARCH model to overcome these symptoms. 


\section{Conclusions}

Based on research on BUKU III banking stocks with stock data from 2010 - 2019, it was found that for BBTN shares produced an average stock return of $0.25 \%$, with the lowest return value of $-28.87 \%$ and the highest return of $20,84 \%$. BDMN shares generate an average stock return of $0.62 \%$ with the lowest return value of $-46.88 \%$ and the highest return of $38.32 \%$. BTPN shares generate an average stock return of $0.12 \%$ with the lowest return value of $-20.33 \%$ and the highest return of $22.04 \%$. MAYA shares generate an average stock return of $0.11 \%$ with the lowest return value of $-71.45 \%$ and the highest return of $52.67 \%$. Bank MEGA shares generate an average stock return of $0.76 \%$ with the lowest return value of $-33.94 \%$ and the highest return of $28.59 \%$. From a time, series perspective on the volatility of stock returns in Banking Book III shows a significant time grouping feature. Clustering is caused by several related factors, for example the increase in banking performance at the end of the year shows a large fluctuation phenomenon which tends to be followed by relatively large fluctuations.

In the volatility of bank stock returns in Book III, there is a clear symptom of heteroscedasticity. The GARCH model can be used in assessing the volatility of stock returns in Book III banking on the IDX. Models that can be used are the GARCH $(1,1)$ model for BBTN, BDMN, BTPN and MAYA stocks, and GARCH $(2,1)$ for MEGA. From the research that has been done for investors who are risk averse, they can choose to invest in MEGA stocks because they have the least risk. Investors who are risk takers can invest in MAYA stocks because they can produce the highest return but also have a greater risk. And for banks and regulators to be able to make policies that can affect the high and low share prices so as to maintain stock price stability

\section{References}

[1] R. F. Engle, “Kingdom Inflation," Society, vol. 50, no. 4, pp. 987-1007, 2011, [Online]. Available: http://www.jstor.org/stable/1912773.

[2] Y. Xia and M. S. Kamel, "A generalized least absolute deviation method for parameter estimation of autoregressive signals," IEEE Trans. Neural Networks, vol. 19, no. 1, pp. 107118, 2008, doi: 10.1109/TNN.2007.902962.

[3] C. M. Lim and S. K. Sek, "Comparing the Performances of GARCH-type Models in Capturing the Stock Market Volatility in Malaysia," Procedia Econ. Financ., vol. 5, no. 13, pp. 478-487, 2013, doi: 10.1016/s2212-5671(13)00056-7.

[4] E. Endri, Z. Abidin, T. P. Simanjuntak, and I. Nurhayati, "Indonesian stock market volatility: GARCH model," Montenegrin J. Econ., vol. 16, no. 2, pp. 7-17, 2020, doi: 10.14254/1800$5845 / 2020.16-2.1$

[5] N. A. Kyriazis, K. Daskalou, M. Arampatzis, P. Prassa, and E. Papaioannou, "Estimating the volatility of cryptocurrencies during bearish markets by employing GARCH models," Heliyon, vol. 5, no. 8, 2019, doi: 10.1016/j.heliyon.2019.e02239.

[6] H. Liu, Z. Zhang, and Q. Zhao, "The volatility of the index of shanghai stock market research based on ARCH and its extended forms," Discret. Dyn. Nat. Soc., vol. 2009, 2009, doi: $10.1155 / 2009 / 743685$.

[7] A. E. M. Ahmed, "MODELING STOCK MARKET VOLATILITY USING GARCH MODELS EVIDENCE Department of Econometrics \& Social Statistics Department of Quantitative Analysis," no. January, 2017.

[8] G. Hojatallah, "Volatility mean reversion and stock market efficiency," Asian Econ. Financ Rev., vol. 13, no. 12, pp. 1681-1692, 2013, [Online]. Available: http://www.aessweb.com/pdffiles/aefr 3(12), 1681-1692.pdf.

[9] L. Hu, "Research on Stock Returns and Volatility-Based on ARCH - GARCH Model," vol. 
156, no. Meici, pp. 181-184, 2017, doi: 10.2991/meici-17.2017.39.

[10] Z. Lin, "Modelling and forecasting the stock market volatility of SSE Composite Index using GARCH models," Futur. Gener. Comput. Syst., vol. 79, pp. 960-972, 2018, doi: 10.1016/j.future.2017.08.033.

[11] R. Bhowmik and S. Wang, "Stock market volatility and return analysis: A systematic literature review," Entropy, vol. 22, no. 5, pp. 1-18, 2020, doi: 10.3390/E22050522.

[12] W. Bonga, "Stock Market Volatility Analysis using GARCH Family Models: Evidence from Zimbabwe Stock Exchange," MPRA Pap., no. 94201, 2019.

[13] J. R. Trapero, M. Cardós, and N. Kourentzes, "Empirical safety stock estimation based on kernel and GARCH models," Omega (United Kingdom), vol. 84, pp. 199-211, 2019, doi: 10.1016/j.omega.2018.05.004.

[14] D. Pradeepkumar and V. Ravi, Forecasting financial time series volatility using Particle Swarm Optimization trained Quantile Regression Neural Network, vol. 58. Elsevier B.V., 2017.

[15] I. Dewia, R. Nurmalina, A. K. Adhi, and B. Brümmer, "Price Volatility Analysis in Indonesian Beef Market," KnE Life Sci., vol. 2, no. 6, p. 403, 2017, doi: 10.18502/kls.v2i6.1062.

[16] K. A. Effendi, "Determining the Best Arch/Garch Model and Comparing JKSE with Stock Index in Developed Countries," The Winners, vol. 16, no. 2, p. 71, 2015, doi: 10.21512/tw.v16i2.1560

[17] P. Hasanah, S. Q. Nasir, and S. Subchan, "Gold Return Volatility Modeling Using Garch," Indones. J. Math. Educ., vol. 2, no. 1, p. 20, 2019, doi: 10.31002/ijome.v2i1.1222.

[18] A. Maqsood, S. Safdar, R. Shafi, and N. J. Lelit, "Modeling Stock Market Volatility Using GARCH Models: A Case Study of Nairobi Securities Exchange (NSE)," Open J. Stat., vol. 07, no. 02, pp. 369-381, 2017, doi: 10.4236/ojs.2017.72026.

[19] M. T. P. D, "FORECASTING STOCK MARKET VOLITILITY- EVIDENCE FROM MUSCAT SECURITY MARKET USING GARCH MODELS Abstract : International Journal of Commerce and Finance 2. The Notification Procedure Economic Competitive Mechanism of Oman 3 . About Oman Capital Market," vol. 2, no. 1, pp. 37-53, 2016.

[20] M. Marobhe and D. Pastory, "Modeling Stock Market Volatility Using GARCH Models Case Study of Dar es Salaam Stock Exchange (DSE)," Rev. Integr. Bus. Econ. Res., vol. 9, no. 2, pp. $138-150,2020$.

[21] V. S. Sembiring, Ferikawita Magdalena Paramita and A. P. Malik, "The Estimation Model for Measuring Performance of Stock Mutual Funds Based on ARCH / GARCH Model," Rev. Integr. Bus. Econ. Res., vol. 5, no. 2, pp. 215-225, 2016.

[22] N. Sariannidis, G. Giannarakis, N. Litinas, and G. Konteos, "A GARCH examination of macroeconomic effects on U.S. stock market: A distinction between the total market index and the sustainability index," Eur. Res. Stud. J., vol. 13, no. 1, pp. 129-142, 2010, doi: $10.35808 / \mathrm{ersj} / 262$.

[23] E. Ugurlu, E. Thalassinos, and Y. Muratoglu, "Modeling Volatility in the Stock Markets using GARCH Models: European Emerging Economies and Turkey,” Int. J. Econ. Bus. Adm., vol. II, no. Issue 3, pp. 72-87, 2014, doi: 10.35808/ijeba/49.

[24] K. E. Lestari, U. S. Karawang, U. S. Pasaribu, and S. Indratno, "Modelling Stock Return Volatility using ARCH and GARCH Models," no. August 2020, 2016.

[25] D. M. Gérald, "Estimating and Forecasting West Africa Stock Market Volatility Using Asymmetric GARCH Models," vol. 8, no. 6, pp. 91-109, 2018.

[26] V. Javed Khan, "Financial Forecasting by Autoregressive Conditional Heteroscedasticity (ARCH) Family: A Case of Mexico," J. Public Policy Adm., vol. 2, no. 3, p. 32, 2018, doi: 10.11648/j.jppa.20180203.13.

[27] F. Ruhani, M. A. I. Islam, and T. S. Tunku Ahmad, "Theories Explaining Stock Price Behavior: A Review of the Literature,” Int. J. Islam. Bank. Financ. Res., vol. 2, no. 2, pp. 5164, 2018, doi: 10.46281/ijibfr.v2i2.215.

[28] Š. Lyócsa and N. Todorova, "Trading and non-trading period realized market volatility: Does it matter for forecasting the volatility of US stocks?,” Int. J. Forecast., vol. 36, no. 2, pp. 628- 
645, 2020, doi: 10.1016/j.ijforecast.2019.08.002.

[29] M. Kannadhasan, B. P. S. Thakur, S. Aramvalarthan, and A. Radhakrishnan, "Modelling volatility in emerging capital market: The case of Indian capital market," Acad. Account. Financ. Stud. J., vol. 22, no. 1, pp. 1-11, 2018.

[30] V. Ngozi, "www.econstor.eu," 2014. 